\title{
Fear-of-falling and associated risk factors in persons with rheumatoid arthritis: a 1 year prospective study
}

\author{
Emma K. Stanmore ${ }^{1,2^{*}} \mathbb{D}$, Jackie Oldham ${ }^{3}$, Dawn A. Skelton ${ }^{4}$, Terence O'Neill ${ }^{5,6}$, Mark Pilling $^{7}$ and Chris Todd ${ }^{1}$
}

\begin{abstract}
Background: Falls, associated injuries and fear-of-falling are common in adults with RA. Fear-of-falling can be a major consequence of, and as debilitating as falling, resulting in a cycle of activity restriction, reduced quality of life, institutionalisation and potentially increase risk of falls. The objective of this study was to examine the relationship between fear-of-falling and risk factors associated with fear-of-falling in adults with rheumatoid arthritis (RA) over a 1 year period.
\end{abstract}

Methods: Five hundred fifty-nine patients with RA were recruited from four outpatient clinics in this prospective cohort study. Baseline assessments included socio-demographic, medical and lifestyle related risk factors. Fall incidence was prospectively obtained monthly using postal cards over a 1 year period. Fear-of-falling was assessed at baseline and 1 year using the Short Falls Efficacy Scale-International (Short FES-I). Logistic regression was used to determine the association between high fear-of-falling (Short FES-I > 11) at baseline (outcome) and a range of putative predictor variables including previous falls, and also baseline factors associated with a high fear-of-falling at follow-up.

Results: Five hundred thirty-five (ninety-six percent) participants (mean age 62.1 yrs.; 18-88 yrs) completed 1 year follow-up and of these, 254 (47\%) completed the Short FES-I questionnaire at 1 year. In a multivariate model, a history of multiple falls $(O R=6.08)$ higher HAQ score $(O R=4.87)$ and increased time to complete the Chair Stand Test $(\mathrm{OR}=1.11)$ were found to be independent predictors of high fear-of-falling and had an overall classification rate of $87.7 \%$. There were no significant differences found in fear-of-falling at 1 year follow-up in those who reported falls during the study, participant's baseline fear appeared to predict future fear, regardless of further falls.

Conclusions: Fear-of-falling is significantly associated with previous falls and predictive of future falls and fear. RA patients would benefit from fall prevention measures whether or not they have previously fallen.

Keywords: Fear-of-falling, Falls, Physical function, Rheumatoid arthritis, Prospective

\footnotetext{
* Correspondence: emma.stanmore@manchester.ac.uk

'School of Health Sciences and Manchester Academic Health Science Centre (MAHSC), Jean McFarlane Building, University Place, University of Manchester, Manchester M13 9LP, UK

${ }^{2}$ Manchester University NHS Foundation Trust, M13 9WL Manchester, UK

Full list of author information is available at the end of the article
}

(c) The Author(s). 2021 Open Access This article is licensed under a Creative Commons Attribution 4.0 International License, which permits use, sharing, adaptation, distribution and reproduction in any medium or format, as long as you give appropriate credit to the original author(s) and the source, provide a link to the Creative Commons licence, and indicate if changes were made. The images or other third party material in this article are included in the article's Creative Commons licence, unless indicated otherwise in a credit line to the material. If material is not included in the article's Creative Commons licence and your intended use is not permitted by statutory regulation or exceeds the permitted use, you will need to obtain permission directly from the copyright holder. To view a copy of this licence, visit http://creativecommons.org/licenses/by/4.0/. The Creative Commons Public Domain Dedication waiver (http://creativecommons.org/publicdomain/zero/1.0/) applies to the data made available in this article, unless otherwise stated in a credit line to the data. 


\section{Introduction}

Patients with rheumatoid arthritis (RA) are at high risk of falls [1-3] and their associated injuries, including fractures and adverse psychological effects [1, 4, 5]. Given the adverse consequences of falls, it is not surprising that many people have a fear-of-falling. Such fear-of-falling can be as debilitating as falling itself and can result in activity restriction, reduced quality of life, increased use of medication, institutionalisation and may also increase the risk of injurious falls [6-10]. Fear-of-falling is not exclusively determined by physical weakness; many people with poor balance or a history of previous falls remain confident and do not report a fear-of-falling [11]. Although having a fall is linked with the development of fear-of-falling, fear-of-falling is not uncommon among those who have never fallen [12-14]. Falls and fear-offalling are not limited to older people and research suggests they may affect younger as well as older adults with RA $[15,16]$. Despite this, there are few data concerning the occurrence and determinants of fear-of-falling among people with RA [3]. Prevalence of fear-of-falling in cross-sectional RA studies shows marked variability (range:16-67\%). This may in part be related to the study population (women only, small samples or frail older patients), inconsistent definitions of fear-of-falling and use of different assessment measures [5, 16-20]. To date, there are no prospective data concerning fear-of-falling or factors which predict fear-of-falling in adults with RA. The aim of this analysis was to determine factors linked with high fear-of-falling in men and women with RA, and factors linked also with the development of fear-offalling.

\section{Methods}

\section{Participants}

Patients with a diagnosis of RA, based on the 2010 American College of Rheumatology classification criteria for RA [21] were consecutively recruited from four rheumatology clinics in the Northwest of England. Participants were excluded from the study if they were under the age of 18 years or if they were unable to give informed consent, as assessed by a trained research nurse. Data collection, analysis and reporting were completed between August 2008 and September 2013 and ethical approval for the study was obtained from the $\mathrm{Na}$ tional Research Ethics Committee, reference 08/H1009/ 41 and written informed consent was obtained in accordance with the Declaration of Helsinki [22].

\section{Baseline assessment}

Participants were assessed at baseline by a trained research nurse. This included an interviewer assisted questionnaire that included socio-demographic questions (gender, age, ethnicity, employment status, marital status), information about falls and fear-of-falling, and the underlying RA. A number of performance measures were also performed (see below).

\section{i). Fear-of-falling, falls}

At baseline the seven-item Short FES-I [23] was completed to measure confidence in performing a range of activities of daily living without falling. Activities include getting dressed or undressed, taking a bath or shower, getting in or out of a chair, going up or down stairs, reaching, walking up or down a slope, going out to a social event. A score is obtained by adding all the scores on all items together to give a total that ranges from 7 (no fear) to 28 (severe concern) [23]. Cut off points have been adopted to differentiate between lower and higher levels of fear-of-falling concern $(7-10=$ low concern, 11-28 = high concern) [11]. Participants were asked at baseline about their 1 year history of falls. A fall was classified using the Prevention of Falls Network Europe (ProFaNE) definition of, "an unexpected event in which participants come to rest on the ground, floor, or other lower level" [24].

\section{ii). Medical and functional assessments}

RA status was assessed using the Disease Activity Score (DAS28) [25]. Self-reported functional status was measured using the Health Assessment Questionnaire (HAQ) that measures patients' perceptions of difficulties in performing activities in daily living, the need for equipment and physical assistance to perform tasks [26]. The validated Falls Risk Assessment Tool (FRAT) was used to measure falls risk [27]. Patients were also asked questions about levels of pain and fatigue using visual analogue scales (VAS) [28, 29], vision [30] and about any previous fractures, surgery, co-morbidities, or joint replacement(s) [31] and all verified using medical records. Medical records were also used to check medication, including steroid use and previous medical history [32]. Lower limb muscle strength was assessed using the Chair Stand Test [33] and balance was measured using the Four-Test Balance Scale [34].

\section{Follow up}

Participants were asked to complete, over a course of a year, monthly follow-up of falls using prepaid, preaddressed calendar postcards that were filled in daily [35]. After 1 year participants were sent a postal questionnaire that included the Short FES-I [23].

\section{Sample size}

The sample size calculation was based on fall rates as this was the primary focus of the study [1]. Based on 
data from retrospective studies $[16,31,36]$ it was calculated that to estimate a fall rate of 0.3 falls/person year. a sample size of 495 (i.e. 550 people before an assumed $10 \%$ drop-out rate) would be able to estimate this to a precision of $+/-0.04$ falls/person year (Clopper-Pearson [37], using StatsDirect version 3.1.14 [38]).

\section{Analysis}

Statistical analysis was conducted using SPSS [39] and R version 3.4.3 [40]. Independent group t-tests for normally distributed data, or the equivalent non-parametric tests were used when appropriate to examine differences between those with low and high fear-of-falling. Paired $\mathrm{t}$-tests or the equivalent non-parametric tests were used to examine differences between baseline and 1 year follow up. Chi-squared tests (or Fisher's Exact test) were used to examine the differences in categorical variables between independent groups. Similarly ANOVA or the equivalent non-parametric test were used to compare between multiple independent groups. Bonferroni adjustments for multiple testing are considered in the interpretation of $p$-values (Table 2). The Short FES-I data (range: 7-28) were transformed into a binary variable indicating low (7-10) and high (11-28) fear-of-falling [11]. Checks were made to ensure that the sample remaining in the follow-up were not systematically different from non-responders. Binary logistic regression was used to calculate odds ratios (OR) and 95\% confidence intervals (CI) for age and gender and all fear-of-falling risk associated variables including salient interaction terms. Model diagnostics (Hosmer-Lemeshow goodness-of-fit test, Q$\mathrm{Q}$ plot for outliers) were checked and were satisfied [41]. Model building was conducted by first examining effect sizes in univariate logistic models using clinically relevant variables, and testing for multi-collinearity (variance inflation factors) in multivariate models. These modelbuilding checks were satisfied.

\section{Results \\ Participants}

A total of 559 participants completed the baseline assessments (Fig. 1) and 535 (96\%) completed follow up of falls and remained in the study at 1 year (incidence of falls data reported elsewhere) [1]. Forty-seven percent $(n=254)$ of the participants completed the second postal Short FES-I questionnaire after 1 year. The mean age of participants was 62.1 years $(\mathrm{SD}=12.8, \quad$ median $=63$; range 18-88) and 386 (69.1\%) were women. The majority of participants were married or living with a partner $(n=378,69.7 \%)$ and were of white British ethnicity and born in the UK $(n=528,94.5 \%)$. Over half of the participants were retired $(n=327,58.5 \%)$, and $14.7 \%$ were unable to work due to their disabilities $(n=82)$. About a quarter of participants $(24 \% ; n=134)$ continued to be employed. The demographic, disease characteristics and fall risk factor variables of the study population at baseline $(n=559)$ and those continuing to the 1 year follow up $(n=254)$ are shown in Table 1 and demonstrate similar characteristics. The characteristics of those participants who did not complete the follow up questionnaire $(n=281,53 \%)$ were also similar to those who did complete.

\section{Occurrence of falls}

Detailed results on the incidence, risk factors and consequences of the falls are reported elsewhere $[1,15]$.

\section{Prevalence of fear-of-falling}

At baseline, $69.9 \%$ of participants scored in the high fear-of-falling range (95\% CI 66.1, 73.7\%). At follow up $71.7 \%$ participants scored in the high fear-of-falling range (95\% CI 65.4, 76.5\%).

\section{Determinants of fear-of-falling}

\section{i). Retrospective data}

Those who reported a fall in the previous year $(n=$ 242) had a significantly higher Short FES-I score at baseline than those who reported no previous falls $(n=17.4$ vs $13.8 ; p<0.001)$. An independent $\mathrm{t}$-test was used to compare the 1 year history of falls and the 1 year follow up Short FES-I score. There were no significant differences between the groups in mean follow up Short FESI scores $(\mathrm{t}=-1.5, \mathrm{df}=480, p=0.1,95 \% \mathrm{CI}-2.6,0.4)$.

Within the items of Short FES-I, getting dressed/undressed and getting into-out of a chair were of much less concern than the other items to the participants at baseline $(p<0.001)$.

Women (mean Short FES-I score $=16.0$ ) had significantly higher fear-of-falling scores than men (mean Short FES-I score $=16.0$ vs 13.9 respectively; $\mathrm{t}=-3.7$, $\mathrm{df}=532, p<0.001,95 \%$ CI $-3.23,-1.01)$. Concerns about fear-of-falling consistently increased with age (in bands of up to 34,35 to 44,45 to 54,65 to 74 and over 75 years; $\mathrm{X}^{2}=12.6, \mathrm{df}=1, p<0.001$ ).

\section{Disease related factors}

When compared with participants who had low fear-offalling, participants who reported high concerns about fear-of-falling generally had more swollen/tender joints, higher DAS28, pain, fatigue and HAQ scores indicating more active RA disease and poorer physical function (all $p \leq 0.002$ ) (Table 2). They also had more co-morbid conditions and had poorer lower limb strength as evidenced by more time needed to complete the five Chair Stand test. 


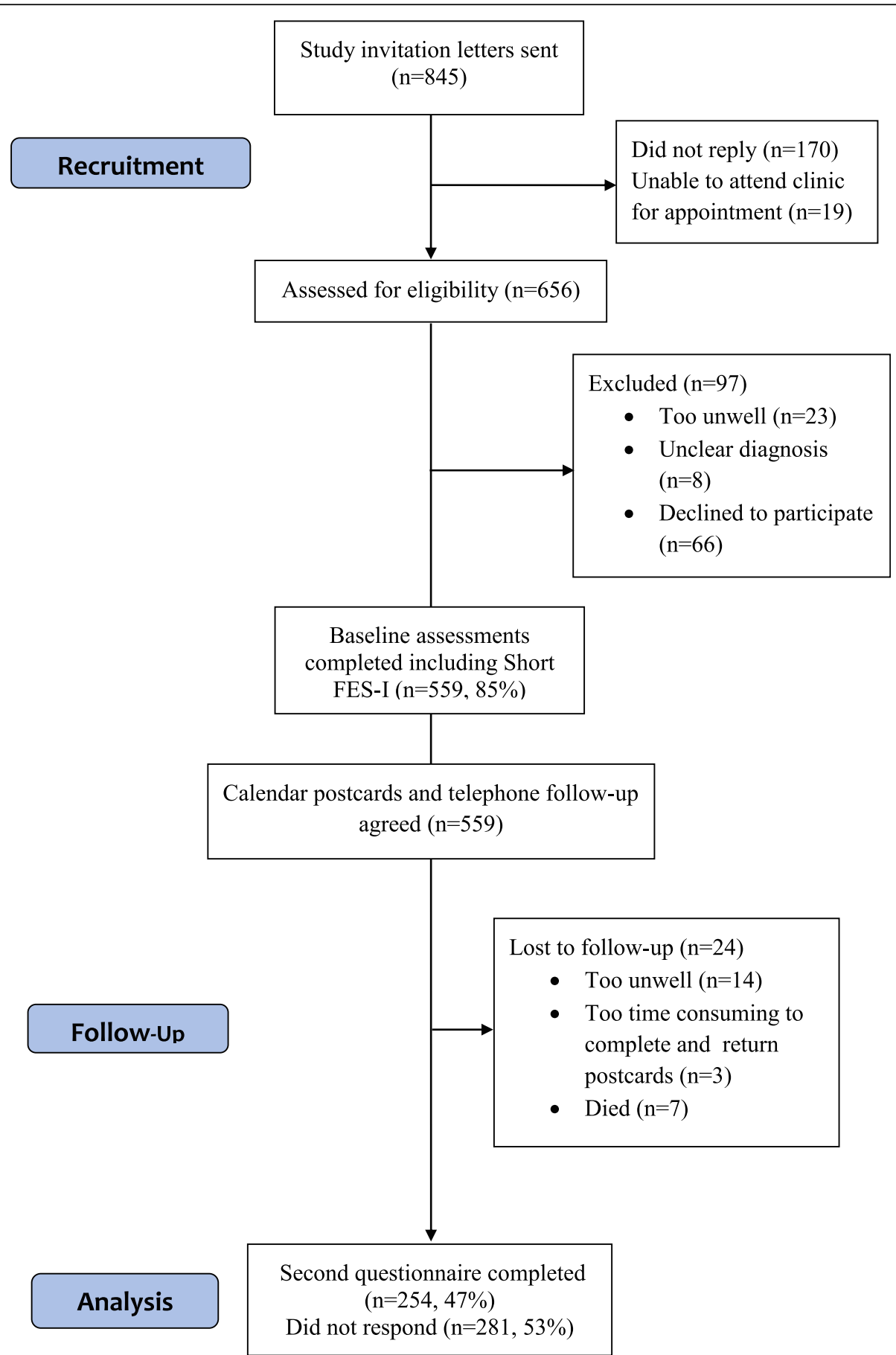

Fig. 1 Flow diagram of study recruitment and follow up

At baseline, participants reporting high fear-of-falling concerns were more likely to be taking psychotropic medication, four or more medicines and steroids. High fear-of-falling levels were also more common in women and high fear-of-falling participants were associated with having a history of one or more falls, a history of stroke or
Parkinson's disease and a history of previous surgery and joint replacements. High levels of fear were also more common in participants who complained of feeling dizzy or unsteady, having painful feet, poorer balance and lower limb strength as tested by the four test balance scale and the ability to perform five chair stands (Table 2). 
Table 1 Participant characteristics at baseline and 1 year follow up

\begin{tabular}{|c|c|c|}
\hline Variable & Baseline $(n=559)$ & 1 year follow up $(n=254)$ \\
\hline \multicolumn{3}{|l|}{ Demographics } \\
\hline Female n (\%) & $386(69.1)$ & $174(68.5)$ \\
\hline $\mathrm{Age}^{\mathrm{a}}$ & $62(12.8)$ & $62(10.0)$ \\
\hline White British n (\%) & $534(95.5)$ & $240(94.5)$ \\
\hline Married/living with partner n (\%) & $378(69.7)$ & 199 (80.6) \\
\hline Employed n (\%) & $134(24.0)$ & $55(21.7)$ \\
\hline \multicolumn{3}{|l|}{ Disease factors } \\
\hline Swollen joints $(0-28)^{a}$ & $4.6(6.2)$ & $4.3(6.0)$ \\
\hline Tender joints $(0-28)^{\mathrm{a}}$ & $5.3(6.9)$ & $5.4(7.0)$ \\
\hline DAS28 score $(0-10)^{a}$ & $4.1(1.6)$ & $4.1(2.6)$ \\
\hline Taking steroids at baseline $\mathrm{n}(\%)$ & $117(20.9)$ & $47(18.5)$ \\
\hline VAS pain score $(0-10)^{a}$ & $3.9(2.6)$ & $3.8(2.6)$ \\
\hline VAS fatigue score $(0-10)^{a}$ & $4.7(2.8)$ & $4.5(2.8)$ \\
\hline HAQ score $(1-4)^{a}$ & $2.4(0.9)$ & $2.4(0.8)$ \\
\hline \multicolumn{3}{|l|}{ Medical history } \\
\hline History of fractures n (\%) & $228(40.8)$ & $107(42.1)$ \\
\hline Poor vision (reg. Blind, v poor or poor) n (\%) & $46(8.2)$ & $19(7.5)$ \\
\hline Number of co-morbidities ${ }^{\text {a }}$ & $2.0(2.0)$ & $1.9(1.9)$ \\
\hline Previous surgery n (\%) & $408(73.0)$ & $187(73.6)$ \\
\hline Previous joint replacements ${ }^{a}$ & $0.2(0.5)$ & $0.2(0.5)$ \\
\hline Injuries from previous falls ${ }^{a} \mathrm{n}(\%)$ & $1.6(1.4)$ & $1.6(1.4)$ \\
\hline \multicolumn{3}{|l|}{ Fall risk factors } \\
\hline History of stroke/Parkinsons n (\%) & $38(6.8)$ & $20(7.9)$ \\
\hline Psychotropic medication n (\%) & $104(18.6)$ & $51(20.1)$ \\
\hline Four or more types of medicines $n(\%)$ & $431(77.1)$ & $196(77.2)$ \\
\hline Feeling dizzy or unsteady n (\%) & $370(66.2)$ & $167(65.7)$ \\
\hline Painful feet n (\%) & 431 (77.2) & $192(75.5)$ \\
\hline Short FES-I score $(7-28)^{a}$ & $15.3(6.5)$ & $14.8(6.3)$ \\
\hline \multicolumn{3}{|l|}{ Four test balance scale } \\
\hline \multicolumn{3}{|l|}{ Fail at each level } \\
\hline Unsuccessful n (\%) & $39(7.0)$ & $13(5.1)$ \\
\hline Feet together stand n (\%) & $13(2.3)$ & $7(2.8)$ \\
\hline Semi-tandem stand n (\%) & $216(38.6)$ & 93 (36.6) \\
\hline Tandem stand n (\%) & $116(20.8)$ & $55(21.7)$ \\
\hline One leg stand n (\%) & $175(31.3)$ & $86(33.9)$ \\
\hline Able to complete 5 chair stands $n(\%)$ & $484(86.6)$ & $217(85.4)$ \\
\hline Time taken for 5 chair stands (Seconds) ${ }^{a}$ & $21.0(12.2)$ & $21.1(13.2)$ \\
\hline
\end{tabular}

amean (SD)

ii). Prospective data

Those who reported a fall during the study had a significantly higher mean baseline Short FES-I score of 16.8 than non- fallers at 14.4 $(\mathrm{t}=-4.3, p<0.001,95 \% \mathrm{CI}-3.5$, $-1.3)$.
To examine whether fear-of-falling increased following a fall, an independent $t$-test was used on the change in Short FES-I score (the difference between follow-up Short FES-I score and baseline Short FES-I score). There were no significant differences in fear-of-falling found between non-fallers and fallers at baseline or follow-up 
Table 2 Fear-of-falling at baseline and 1 year follow-up

\begin{tabular}{|c|c|c|c|c|}
\hline Variable & $\begin{array}{l}\text { Baseline high fear-of- } \\
\text { falling } \\
(n=390)^{\text {b }}\end{array}$ & $\begin{array}{l}\text { Baseline low fear of } \\
\text { falling } \\
(n=168)\end{array}$ & $\begin{array}{l}\text { Follow up high fear-of- } \\
\text { falling } \\
(n=181)\end{array}$ & $\begin{array}{l}\text { Follow up low fear-of- } \\
\text { falling } \\
(n=73)\end{array}$ \\
\hline \multicolumn{5}{|l|}{ Demographics } \\
\hline Female (n/\%) & $287(73.6)^{* *}$ & 99 (58.9) & $122(67.4)$ & $52(71.2)$ \\
\hline $\mathrm{Age}^{\mathrm{a}}$ & $63(12.7)^{* *}$ & $59.9(12.7)$ & $62(10.7)^{* *}$ & $62(10.0)$ \\
\hline \multicolumn{5}{|l|}{ Disease factors } \\
\hline Swollen joints $(0-28)^{a}$ & $5(6.7)^{* *}$ & $3(4.7)$ & $5.0(6.4)^{* *}$ & $2.6(4.4)$ \\
\hline Tender joints (0-28) ${ }^{a}$ & $6(7.3)^{* *}$ & $3(4.9)$ & $6(7.2)^{* *}$ & $4.1(6.3)$ \\
\hline DAS28 score $(0-10)^{a}$ & $5(1.5)^{* *}$ & $3(1.4)$ & $5(1.5)^{* *}$ & $3(1.6)$ \\
\hline Taking steroids at baseline ( $\mathrm{n} / \%)$ & $94(24.1)^{*}$ & $23(13.7)$ & $42(23.2)^{* *}$ & $5(6.8)$ \\
\hline VAS pain score $(0-10)^{\mathrm{a}}$ & $5(2.6)^{* *}$ & $3(2.2)$ & $4(2.5)^{* *}$ & $3(2.3)$ \\
\hline VAS fatigue score $(0-10)^{\mathrm{a}}$ & $5(2.6)^{* *}$ & $3(2.6)$ & $5(2.6)^{* *}$ & $3(2.6)$ \\
\hline HAQ score $(1-4)^{a}$ & $3(0.7)^{* *}$ & $2(0.5)$ & $3(0.8)^{* *}$ & $2(0.6)$ \\
\hline \multicolumn{5}{|l|}{ Medical history } \\
\hline History of fractures (n/\%) & $162(41.5)$ & $65(38.7)$ & $82(45.3)$ & $25(34.2)$ \\
\hline $\begin{array}{l}\text { Poor vision (reg. Blind, v poor or } \\
\text { poor) }(n / \%)\end{array}$ & $37(9.5)$ & $9(5.4)$ & $13(7.2)$ & $6(8.2)$ \\
\hline Previous surgery (n/\%) & $291(74.6)$ & $116(69.0)$ & $137(75.7)$ & $50(68.5)$ \\
\hline Previous joint replacements (n/\%) & 99 (25.6) & $26(15.5)$ & $44(24.6)$ & $15(15.1)$ \\
\hline $\begin{array}{l}\text { History of injuries from previous falls } \\
(\mathrm{n} / \%)\end{array}$ & $107(30.7)^{* *}$ & $17(11.6)$ & $48(29.8)^{*}$ & $8(12.1)$ \\
\hline \multicolumn{5}{|l|}{ Fall risk factors } \\
\hline No falls in previous year (n/\%) & $190(48.7)^{* *}$ & $126(75.0)$ & $91(50.3)^{* *}$ & $54(74.0)$ \\
\hline $\begin{array}{l}\text { History of single fall in previous year } \\
(\mathrm{n} / \%)\end{array}$ & $87(22.3)$ & $33(19.6)$ & $42(23.2)$ & $13(17.8)$ \\
\hline $\begin{array}{l}\text { History of multiple falls in previous } \\
\text { year }(n / \%)\end{array}$ & $113(29.0)$ & $9(5.4)$ & $48(26.5)$ & $6(8.2)$ \\
\hline History of stroke/Parkinson's (n/\%) & $31(7.9)$ & $7(4.2)$ & $18(9.9)$ & $2(2.7)$ \\
\hline Psychotropic medication (n/\%) & $87(22.3)^{* *}$ & $17(10.1)$ & $40(22.1)$ & $11(15.1)$ \\
\hline $\begin{array}{l}\text { Four or more types of medicines ( } \mathrm{n} / \\
\%)\end{array}$ & $328(84.1)^{* *}$ & $103(61.3)$ & $148(81.8)^{*}$ & $48(65.8)$ \\
\hline Feeling dizzy or unsteady (n/\%) & $312(80.0)^{* *}$ & $57(33.9)$ & $136(75.1)^{* *}$ & $31(42.5)$ \\
\hline Painful feet (n/\%) & $321(82.5)^{* *}$ & $109(64.9)$ & $143(79.4)$ & $48(65.8)$ \\
\hline \multicolumn{5}{|l|}{ Four test balance scale (n/\%) } \\
\hline \multicolumn{5}{|l|}{ Fail at each level } \\
\hline Unsuccessful & $39(10.0)^{* *}$ & $0(0.0)$ & $13(7.2)^{* *}$ & $0(0.0)$ \\
\hline Feet together stand & $13(3.3)$ & $0(0.0)^{*}$ & $6(3.3)$ & $1(1.4)$ \\
\hline Semi-tandem stand & $177(45.4)$ & $39(23.2)^{*}$ & 75 (41.4) & $18(24.7)$ \\
\hline Tandem stand & $81(20.8)$ & $34(20.2)^{*}$ & $41(22.7)$ & 14 (19.2) \\
\hline One leg stand & $80(20.5)$ & $95(56.6)^{*}$ & $46(25.4)$ & $40(54.8)$ \\
\hline Able to complete 5 chair stands ( $n / \%)$ & $316(81.0)^{* *}$ & $167(99.4)$ & $145(80.1)^{* *}$ & 72 (98.6) \\
\hline
\end{tabular}

Bonferroni adjustment for multiple testing suggests $p<5 \% / 25=0.002$ for significance in comparisons at baseline, or comparisons at follow up

${ }^{*} P \leq 0.01$

**P $\leq 0.002$

${ }^{\mathrm{a}}$ Mean (SD)

${ }^{\mathrm{b}}$ Data missing for 1 participant 
$(\mathrm{t}=0.8, \mathrm{df}=249, p=0.41)$. Therefore, having a fall or not in the 1 year follow up did not appear significantly to change levels of fear-of-falling in this group of participants.Short FES-I scores did not differ between women and men at 1 year follow up (mean Short FES-I score $=$ 15.3 vs 15.9 respectively; $\mathrm{t}=0.8, \mathrm{df}=252, p=0.41,95 \%$ CI $-0.9,2.3)$. There were also no significant differences in levels of fear-of-falling with age (in bands of up to 34, 35 to 44,45 to 54,65 to 74 and over 75 year; $\chi^{2}=0.07$, $\mathrm{df}=1, p=0.8)$.

\section{Predictors of fear-of-falling}

Following multivariable binary logistic regression, statistically significant variables were: a history of multiple falls (OR $=5.4,95 \%$ CI 1.8 to $16.3, p=0.02)$; painful feet $(\mathrm{OR}=2.3,95 \% \mathrm{CI} 1.1$ to $4.52, p=0.03)$, increased HAQ score $(\mathrm{OR}=7.8,95 \% \mathrm{CI} 3.9$ to $15.6, p<0.001)$, feeling dizzy or unsteady (OR $=3.8,95 \%$ CI 2.0 to $7.2, \mathrm{p}<0.001)$ and increased time to complete the Chair Stand Test $(\mathrm{OR}=1.1,95 \% \mathrm{CI} 1.0$ to $1.1, p=0.048)$. There was an inverse association between high fear-of-falling and swollen joints $(\mathrm{OR}=0.9,95 \% \mathrm{CI} 0.85$ to $0.99, p=0.02)$ (Table 3). The fit of the predicted values in this logistic regression model was $85.5 \%$ and these results were also supported by a sensitivity analyses using bootstrapping (1000).

A history of multiple falls $(\mathrm{OR}=6.08,95 \%$ CI 1.19 to 30.99, $p=0.03)$, higher HAQ scores $(\mathrm{OR}=4.87,95 \% \mathrm{CI}$ 1.59 to $14.92, p=0.006$ ) and increased time to complete the Chair Stand Test $(\mathrm{OR}=1.11,95 \%$ CI 1.01 to 1.20 , $p=0.02$ ) were found to be the most significant predictors for future fear-of-falling (Table 4). Previous fear predicts future fear and 1 year later fear appeared to be lower amongst women than men. This model had an overall rate of correct classification of $87.7 \%$. A sensitivity analyses using bootstrapping also supported these conclusions from the multivariate logistic regression model.

\section{Discussion}

This is the first study that has prospectively investigated fear-of-falling and predictors for fear-of-falling in a sample of adults with RA. This study demonstrates that fearof-falling is an important problem for adults of all ages with RA with some $70 \%$ of the population experiencing high levels of fear-of-falling, not limited to older people. Mean fear-of-falling scores were in the high fearful category for participants at baseline and at 1 year follow up and the prevalence of fear-of-falling appeared to increase with age and to be higher in women. This is consistent with community dwelling studies [8] and fear-related avoidance of activities is known to be predictive of future falls, physical frailty and reduced muscle strength [12]. Fear-of-falling in people with RA may affect their ability to carry out activities of daily living, such as going out to do shopping or to participate in a social event and so have negative psychological as well as physical consequences [5].

The prevalence of fear-of-falling in this study is higher than previous cross-sectional studies in those with RA that measured having fear or not $[5,16,43]$ but this likely reflects the difference in measurement (Short FESI vs single item measure). Having a fall or not in the 1 year follow up did not appear significantly to change levels of fear-of-falling in this group of participants. Those who fell in the previous 1 year may already experience higher levels of fear-of-falling that remain constant whether they fell again or not in the following 1 year.

Having had at least one previous fall was found to be an independent risk factor for fear-of-falling and nearly tripled the odds of having fear-of-falling. Increasing HAQ scores (but not disease activity scores) and increasing time to complete the Chair Stand Test (indicating a decrease in physical functioning) are other important independent risk factors for fear-of-falling. These results are similar to other studies that have demonstrated an association between functional decline and fear-of-falling in patients with RA $[5,19,42,43]$ and may be helpful in designing a screening tool for modifiable risk factors for patients at risk of fear-of-falling. By asking questions in routine assessments and reviews about fear-of-falling, falls and their context, health and social care practitioners may identify patients who may be at risk of falling. If there is concern that a person is at risk of falling, they can be referred to, or advised to see, a healthcare professional particularly a geriatrician or physiotherapist or falls prevention service if available, to further assess their risk and treat modifiable risk factors. Thus a recommendation for clinicians from this study would be to routinely monitor fear-of-falling amongst patients using a validated tool such as the Short FES-I.

A systematic review and meta-analysis of 30 trials by Kumar and colleagues found that exercise interventions (aimed at reducing falls) that included gait, balance, coordination, strength, resistance and functional tasks are associated with a small to moderate reduction of fear-offalling in community-dwelling older adults [44]. However, a high risk of bias was noted throughout the included trials and so these results should be interpreted with caution, especially as most studies were short term with little long term follow-up to examine if the effect was sustained. There is good evidence that the homebased Otago exercise programme (OEP) [45] and groupbased Falls Management Exercise (FaME) [46] strength and balance programmes are effective in reducing falls if progressive, tailored and reach a minimum effective dose. However, no study to date has investigated the 
Table 3 Associations between risk factors and baseline fear-of-falling using multivariable binary logistic regression (high fear, $n=$ 390/low fear, $n=168$ )

\begin{tabular}{|c|c|c|c|c|}
\hline Risk factor & Score & $\begin{array}{l}\text { Odds ratio } \\
\text { (OR) }\end{array}$ & OR 95\% Confidence Intervals & $p$-value \\
\hline Gender & $\begin{array}{l}\text { Male (referent) } \\
\text { Female }\end{array}$ & 1.24 & $0.64,2.37$ & 0.65 \\
\hline Age & $18-88$ & 0.97 & $0.95,1.00$ & 0.1 \\
\hline Number of swollen joints & $0-28$ & 0.91 & $0.85,0.99$ & 0.02 \\
\hline Number of tender joints & $0-28$ & 0.97 & $0.89,1.04$ & 0.4 \\
\hline DAS28 Score & $0.1-8.9$ & 1.37 & $0.95,1.99$ & 0.1 \\
\hline \multirow[t]{2}{*}{ Psychotropic medicines } & No (referent) & 1.15 & $0.44,3.00$ & 0.8 \\
\hline & Yes & & & \\
\hline \multirow[t]{2}{*}{ Four or more types of medicines } & No (referent) & 1.74 & $0.82,3.68$ & 0.1 \\
\hline & Yes & & & \\
\hline \multirow[t]{2}{*}{ Taking steroids at baseline } & No (referent) & 1.33 & $0.58,3.03$ & 0.5 \\
\hline & Yes & & & \\
\hline \multirow[t]{2}{*}{ History of stroke or Parkinson's disease } & No (referent) & 0.53 & $0.14,1.92$ & 0.3 \\
\hline & Yes & & & \\
\hline VAS pain score & $0-10$ & 1.00 & $0.85,1.16$ & 0.9 \\
\hline VAS fatigue score & $0-10$ & 1.03 & $0.90,1.17$ & 0.7 \\
\hline History of falls in previous 12 months & $\begin{array}{l}0 \text { fall (referent) } \\
1 \text { fall } \\
2 \text { or more falls }\end{array}$ & $\begin{array}{l}1.56 \\
\mathbf{5 . 4 3}\end{array}$ & $\begin{array}{l}0.70,3.52 \\
\mathbf{1 . 8 1 , 1 6 . 2 7}\end{array}$ & $\begin{array}{l}0.3 \\
\mathbf{0 . 0 0 3}\end{array}$ \\
\hline Number of joint replacement & $0-6$ & 0.87 & $0.57,1.33$ & 0.5 \\
\hline \multirow[t]{2}{*}{ History of previous injuries } & No (referent) & 1.11 & $0.48,2.57$ & 0.8 \\
\hline & Yes & & & \\
\hline \multirow[t]{2}{*}{ History of previous surgery } & No (referent) & 0.66 & $0.33,1.30$ & 0.2 \\
\hline & Yes & & & \\
\hline \multirow[t]{2}{*}{ Painful feet } & No (referent) & 2.34 & $1.11,4.52$ & 0.025 \\
\hline & Yes & & & \\
\hline HAQ score & $1.00-4.00$ & 7.79 & $3.87,15.69$ & $<0.001$ \\
\hline \multicolumn{5}{|l|}{ Four test balance scale ${ }^{a}$ : } \\
\hline Semi- tandem stand & 2 & 1.15 & $0.50,2.64$ & 0.7 \\
\hline Tandem stand & 3 & 0.71 & $0.30,1.67$ & 0.4 \\
\hline One - leg stand & 4 (referent) & & & \\
\hline \multirow[t]{2}{*}{ Complaints of feeling dizzy or unsteady } & No (referent) & 3.81 & $2.01,7.22$ & $<0.001$ \\
\hline & Yes & & & \\
\hline Time taken for chair stand test & $4-104 s$ & 1.05 & $1.00,1.10$ & 0.048 \\
\hline
\end{tabular}

Hosmer-Lemeshow goodness of fit test.

$\mathrm{x}^{2}=5.0, \mathrm{df}=8, p=0.759$. Nagelkerke $\mathrm{R}^{2}=61.3 \%$

a Unable to add 'feet together stand' category as too few participants

effectiveness of these programmes specifically with patients with RA. Therefore, well designed future studies are needed to investigate whether exercise interventions are effective in reducing fear-of-falling, and falls in adults with RA.

This study has a number of limitations, these include the falls recorded during the study rely on self-report, low follow up response rate for the Short- FES-I and the method of recruitment of the participants from rheumatology clinics that may have resulted in participants with more moderate to severe RA or more progressive disease than the general primary care population. A measure of physical activity may have given further insight into whether fear-of-falling affected levels of activity. The rheumatology clinics were all based in the Northwest of England and therefore, the results should be interpreted with caution as they may not be generalisable to other populations. 
Table 4 Associations between risk factors and 1 year fear-of-falling using multivariable binary logistic regression (high fear, $n=181 /$ low fear, $n=73$ )

\begin{tabular}{|c|c|c|c|c|}
\hline Risk factor & Score & $\begin{array}{l}\text { Odds ratio } \\
\text { (OR) }\end{array}$ & OR 95\% Confidence Intervals & $p$-value \\
\hline \multirow[t]{2}{*}{ Gender } & Male (referent) & 0.21 & $0.07,0.63$ & 0.05 \\
\hline & Female & & & \\
\hline Age & $18-88$ & 0.95 & $0.89,1.00$ & 0.06 \\
\hline Number of swollen joints & $0-28$ & 0.99 & $0.86,1.13$ & 0.8 \\
\hline Number of tender joints & $0-28$ & 0.92 & $0.82,1.03$ & 0.1 \\
\hline DAS28 Score & $0.1-8.9$ & 1.31 & $0.70,2.44$ & 0.4 \\
\hline \multirow[t]{2}{*}{ Psychotropic medicines } & No (referent) & 1.11 & $0.31,4.00$ & 0.9 \\
\hline & Yes & & & \\
\hline \multirow[t]{2}{*}{ Four or more types of medicines } & No (referent) & 0.81 & $0.26,2.52$ & 0.7 \\
\hline & Yes & & & \\
\hline \multirow[t]{2}{*}{ Taking steroids at baseline } & No (referent) & 3.60 & $0.82,15.74$ & 0.09 \\
\hline & Yes & & & \\
\hline \multirow[t]{2}{*}{ History of stroke or Parkinson's disease } & No (referent) & 1.30 & $0.16,10.47$ & 0.8 \\
\hline & Yes & & & \\
\hline VAS pain score & $0-10$ & 0.96 & $0.75,1.22$ & 0.7 \\
\hline VAS fatigue score & $0-10$ & 1.19 & $0.96,1.46$ & 0.1 \\
\hline History of falls in previous 12 months & $\begin{array}{l}0 \text { fall (referent) } \\
1 \text { fall } \\
2 \text { or more falls }\end{array}$ & $\begin{array}{l}2.44 \\
6.08\end{array}$ & $\begin{array}{l}0.68,8.71 \\
1.19,30.99\end{array}$ & $\begin{array}{l}0.2 \\
\mathbf{0 . 0 3}\end{array}$ \\
\hline Number of joint replacements & $0-6$ & 0.83 & $0.23,3.04$ & 0.8 \\
\hline \multirow[t]{2}{*}{ History of injuries from previous falls } & No (referent) & 0.81 & $0.22,2.95$ & 0.8 \\
\hline & Yes & & & \\
\hline \multirow[t]{2}{*}{ History of previous surgery } & No (referent) & 1.15 & $0.41,3.28$ & 0.8 \\
\hline & Yes & & & \\
\hline \multirow[t]{2}{*}{ Painful feet } & No (referent) & 0.92 & $0.32,2.64$ & 0.8 \\
\hline & Yes & & & \\
\hline HAQ score & $1.00-4.00$ & 4.87 & $1.59,14.92$ & 0.006 \\
\hline \multicolumn{5}{|l|}{ Four test balance scale ${ }^{a}$ : } \\
\hline Semi- tandem stand & 2 & 0.81 & $0.24,2.69$ & 0.7 \\
\hline Tandem stand & 3 & 1.40 & $0.37,5.40$ & 0.6 \\
\hline One - leg stand & 4 (referent) & & & \\
\hline \multirow[t]{2}{*}{ Complaints of feeling dizzy or unsteady } & No (referent) & 1.67 & $0.65,4.27$ & 0.29 \\
\hline & Yes & & & \\
\hline Time taken for chair stand test & $4-104 s$ & 1.11 & $1.01,1.20$ & 0.02 \\
\hline \multirow[t]{2}{*}{ Baseline fear-of-falling } & Low (referent) & 30.05 & $1.42,637.18$ & 0.03 \\
\hline & High & & & \\
\hline
\end{tabular}

Hosmer-Lemeshow goodness of fit test

$\mathrm{x}^{2}=6.9, \mathrm{df}=8, p=0.545$. Nagelkerke $\mathrm{R}^{2}=58.6 \%$

a Unable to add 'feet together stand' category as too few participants

\section{Conclusions}

Fear-of-falling is common in adults with RA and this may alter activity levels and social engagement and may affect the ability to function independently. Fear-of-falling is significantly associated with previous falls and markers of poor function and is predictive of future falls and future fear. RA patients who report high fear-of-falling may benefit from fall prevention measures whether or not they have previously fallen, and exercise interventions to reduce fear-of-falling should also be considered. 


\section{Abbreviations}

Cl: Confidence Interval; DAS28: Disease Activity Score 28 joints; FaME: Falls Management Exercise; FRAT: Falls Risk Assessment Tool; HAQ: Health Assessment Questionnaire; OEP: Otago exercise programme; ProFaNE: Prevention of Falls Network Europe; RA: Rheumatoid arthritis; Short FES-I: Short Falls Efficacy Scale-International; VAS: Visual Analogue Scale

\section{Acknowledgements}

Special thanks to all the participants involved in the research and also the nursing and administration staff who supported the data collection phase of the study at Manchester Academic Health Science Centre (MAHSC). The authors would also like to thank Professor I. Bruce, Prof A. Hassell, Dr. S. Ryan, Mr. P. New for their assistance in accessing patients. Thanks to Dr. M. Campbell for initial statistical support and Professor A.J. Campbell and Professor M. Clare Robertson for their advice throughout the study.

\section{Authors' contributions}

Each author has made substantive intellectual contributions to this study: ES conceived the study. ES, CT, JO, DS and TO were responsible for the design of the study and obtaining funding. MP and ES were responsible for the analysis and interpretation of the data and preparation of the manuscript. ES and MP conducted data analyses. All authors read and approved the final manuscript.

\section{Funding}

This study was funded by Versus Arthritis (18010) and a small grant from the Wellcome Trust Clinical Research Facility, Manchester (06834). The authors of this report are responsible for its content. Statements in the report should not be construed as endorsement by Arthritis Research UK, the MRC, or the Wellcome Trust Clinical Research Facility, Manchester.

\section{Availability of data and materials}

The datasets analysed during the current study are available from the corresponding author on reasonable request.

\section{Ethics approval and consent to participate}

This study was conducted with the approval of the National Research Ethics Committee, reference 08/H1009/41. All participants gave written, informed consent.

\section{Consent for publication}

Not applicable.

\section{Competing interests}

The authors declare that they have no competing interests.

\section{Author details}

${ }^{1}$ School of Health Sciences and Manchester Academic Health Science Centre (MAHSC), Jean McFarlane Building, University Place, University of Manchester, Manchester M13 9LP, UK. ${ }^{2}$ Manchester University NHS Foundation Trust, M13 9WL Manchester, UK. ${ }^{3}$ School of Health Sciences, Citylabs, Nelson Street, University of Manchester, Manchester M13 9LP, UK. ${ }^{4}$ School of Health and Life Sciences, Glasgow Caledonian University, Cowcaddens Rd, Glasgow G4 OBA, UK. ${ }^{5}$ Versus Arthritis Centre for Epidemiology and Centre for Musculoskeletal Research, University of Manchester, Manchester M13 9PT, UK. ${ }^{6}$ Department of Rheumatology, Salford Royal National Health Service Foundation Trust, Salford M6 8HD, UK. ${ }^{7}$ Behaviour and Health Research Unit, Forvie Site, University of Cambridge School of Clinical Medicine, Box 113 Cambridge Biomedical Campus, Cambridge CB2 OSR, UK.

Received: 18 September 2020 Accepted: 10 February 2021 Published online: 10 March 2021

\section{References}

1. Stanmore EK, Oldham J, Skelton D, O'Neill T, Pilling M, Campbell A, J, et al. Fall incidence and outcomes of falls in a prospective study of adults with rheumatoid arthritis. Arthritis Care Res. 2013;65:737-44.

2. Hayashibara M, Hagino H, Katagiri H, Okano T, Okada J, Teshima R. Incidence and risk factors of falling in ambulatory patients with rheumatoid arthritis: a prospective 1-year study. Osteoporos Int. 2010;21:1825-33.
3. Smulders E, Schreven C, Weerdesteyn V, Van Den Hoogen FHJ, Laan R, Van Lankveld W. Fall incidence and fall risk factors in people with rheumatoid arthritis. Ann Rheum Dis. 2009;68:1795-6.

4. Cooper C, Coupland C, Mitchell M. Rheumatoid arthritis, corticosteroid therapy and hip fracture. Ann Rheum Dis. 1995;54:49-52.

5. Fessel KD, Nevitt MC. Correlates of fear-of-falling and activity limitation among persons with rheumatoid arthritis. Arthritis Care Res. 1997;10:222-8.

6. Trombetti A, Reid KF, Hars M, Herrman FR, Pasha E, Phillips EM, et al. Ageassociated declines in muscle mass, strength, power, and physical performance: impact on fear-of-falling and quality of life. Osteoporos Int. 2016;27:463.

7. Kendrick D, Kumar A, Carpenter H, Zijlstra GAR, Skelton DA, Cook JR, et al. Exercise for reducing fear-of-falling in older people living in the community. Cochrane Database Syst Rev. 2014;11:CD009848.

8. Scheffer AC, Schuurmans MJ, van Dijk N, van der Hooft T, de Rooij SE. Fearof-falling: measurement strategy, prevalence, risk factors and consequences among older persons. Age Ageing. 2008;37:19-24.

9. Lord SR. Predictors of nursing home placement and mortality of residents in intermediate care. Age Ageing. 1994;23:499-504

10. Arfken CL, Lach HW, Birge SJ, Miller JP. The prevalence and correlates of fear-of-falling in elderly persons living in the community. Am J Public Health. 1994;84:565-70.

11. Delbaere K, Close JCT, Mikolaizak AS, Sachdev PS, Brodaty H, Lord SR. The falls efficacy scale international (short FES-I). A comprehensive longitudinal validation study. Age Ageing. 2010;39:210-6.

12. Delbaere K, Crombez G, Vanderstraeten G, Willems T, Cambier D. Fearrelated avoidance of activities, falls and physical frailty: a prospective community-based cohort study. Age Ageing. 2004;33:368-73.

13. Yardley $\mathrm{L}$, Smith $\mathrm{H}$. A prospective study of the relationship between feared consequences of falling and avoidance of activity in community-living older people. Gerontologist. 2002;1:17-23.

14. Chandler JM, Duncan PW, Sanders L, Studentski S. The fear-of-falling syndrome: relationship to falls, physical performance and activities of daily living in the community. Top Geriatr Rehabil. 1996;11:55-63.

15. Stanmore EK, Oldham J, Skelton D, O'Neill T, Pilling M, Campbell AJ, et al. A prospective study of fall risk factors in adults with rheumatoid arthritis. Arthritis Care Res. 2013;65:1251-8.

16. Jamison M, Neuberger GB, Miller PA. Correlates of falls and fear-of-falling among adults with rheumatoid arthritis. Arthritis Rheum. 2003;49:673-80.

17. Bahha J, Amine B, Erraoui M, Boujenone S, Fellous S, El Binoune I, et al. Fearof-falling and foot pain, impairment and disability in rheumatoid arthritis. Ann Rheum Dis. 2017;6:1163.

18. Delialioglu SU, Kamaci GK, Ozel S, Yurdakul F, Bodur H. Evaluation of the factors related with risk of falling and fear-of-falling in patients with rheumatoid arthritis. Ann Rheum Dis. 2017;76:818.

19. Duyur Çakit B, Nacir B, Erdem HR, Karagöz A, Saraçoğlu M. Fear-of-falling, fall risk and disability in patients with rheumatoid arthritis. Turk J Rheumatol. 2011;26:217-25.

20. Yamagiwa K, lijima S, Furuya T, Ikai T, Inoue E, Taniguchi A, et al. Incidence of falls and fear-of-falling in Japanese patients with rheumatoid arthritis. Mod Rheumatol. 2011;21:51-6.

21. Aletaha D, Neogi T, Silman AJ, Funovits J, Felson DT, Bingham CO, et al. Rheumatoid arthritis classification criteria: an American College of Rheumatology/European league against rheumatism collaborative initiative. Arthritis Rheum. 2011;62:2569-81.

22. Sprumont D, Girardin S, Lemmens T. The declaration of Helsinki and the law: an international and comparative analysis. In: Frewer A, Schmidt U, editors. History and theory of human experimentation: the declaration of Helsinki and modern medical ethics. Stuttgart: Franz Steiner Verlag; 2007.

23. Kempen GI, Yardley L, van Haastregt JC, Zijlstra GA, Beyer N, Hauer K, et al The short FES-I: a shortened version of the falls efficacy scale-international to assess fear-of-falling. Age Ageing. 2008;37:44-50.

24. Lamb SE, Jorstad-Stein EC, Hauer K, Becker C. Development of a common outcome data set for fall injury prevention trials: the prevention of falls network Europe consensus. J Am Geriatr Soc. 2005;53:1618-22.

25. Van Riel PLCM, Schumacher HR. How does one assess early rheumatoid arthritis in daily clinical practice? Best Pract Res Clin Rheumatol. 2001;15:6776.

26. Ramey DR, Fries JF, Singh G. The Health Assessment Questionnaire 1995 status and review. In: Spilker B, editor. Pharmacoeconomics and Quality of Life in Clinical Trials. 2nd ed. Philadelphia: Lippincott-Raven; 1996. 
27. Nandy S, Parsons S, Cryer C, Underwood M, Rashbrook E, Carter Y, et al. Development and preliminary examination of the predictive validity of the falls risk assessment tool (FRAT) for use in primary care. J Pub Health. 2004; 26:138-43.

28. Murphy DF, McDonald A, Power C, Unwin A, Macsullivan R. Measurement of pain: a comparison of the visual analogue scale with a non-visual analogue scale. Clin J Pain. 1988;3:197-9.

29. Pollard LC, Choy EH, Gonzalez B, Scott DL. Fatigue in rheumatoid arthritis reflects pain not disease activity. Rheumatology. 2006;45:885-9.

30. Mangione CM, Lee PP, Gutierrez PR, Spritzer K, Berry S, Hays RD. Development of the 25-item National eye Institute visual function questionnaire. Arch Ophthalmol. 2001;119:1050-8.

31. Oswald AE, Pye SR, O'Neill TW, Bunn D, Gaffney K, Marshall T. Prevalence and associated factors for falls in women with established inflammatory polyarthritis. J Rheumatol. 2006;33:690-4.

32. Kaz Kaz H. Johnson D. Kerry S. Chinappen U. Tweed K, Patel S. Fall-related risk factors and osteoporosis in women with rheumatoid arthritis. Rheumatology. 2004;42:1267-71.

33. Guralnik JM, Simonsick EM, Ferrucci L, Glynn RJ, Berkman LF, Blazer DG. A short physical performance battery assessing lower extremity function: association with self reported disability and prediction of mortality and nursing home admission. J Gerontol. 1994;49:M85-94.

34. Rossiter-Fornoff JE, Wolf SL, Wolfson LI, Buchner DM, the FICSIT Group. A cross-sectional validation study of the FCSIT common database static balance measures. J Gerontol. 1995;50A:M291-7.

35. Schwenk M, Lauenroth A, Stock C, Moreno RR, Oster P, McHugh G, et al. Definitions and methods of measuring and reporting on injurious falls in randomised controlled fall prevention trials: a systematic review. BMC Med Res Methodol. 2012;12:50.

36. Armstrong C, Swarbrick CM, Pye SR, O'Neill TW. Occurrence and risk factors for falls in rheumatoid arthritis. Ann Rheum Dis. 2005;64:1602-4.

37. Clopper C, Pearson ES. The use of confidence or fiducial limits illustrated in the case of the binomial. Biometrika. 1934;26:404-13.

38. StatsDirect Ltd. StatsDirect statistical software. England: StatsDirect Ltd.2017 Accessed 8 June 2020 Available from: https://www.statsdirect.com/FAQ.a spx.

39. IBM Corp. IBM SPSS statistics for windows, version 24.0. Armonk: IBM Corp; 2016.

40. R Core Team R: A language and environment for statistical computing. 2017. R Foundation for Statistical Computing, Vienna. Accessed 8 June 2020. Available from www.R-project.org/.

41. Hosmer D, Lemeshow S, Sturdivant RX. Applied logistic regression. 3rd ed. Chichester: Wily; 2013.

42. Morpeth T, Brenton-Rule A, Carroll M, Frecklington M, Rome K. Fear-offalling and foot pain, impairment and disability in rheumatoid arthritis: a case-control study. Clin Rheumatol. 2016;35:887.

43. Furuya T, Yamagiwa K, Ikai T, Inoue E, Taniguchi A, Momohara S, Yamanaka H. Associated factors for falls and fear-of-falling in Japanese patients with rheumatoid arthritis. Clin Rheumatol. 2009;28:1325-30.

44. Kumar A, Delbaere K, Zijlstra GAR, Carpenter H, lliffe S, Masud T, Skelton D, Morris $R$, Kendrick D. Exercise for reducing fear-of-falling in older people living in the community: Cochrane systematic review and meta-analysis. Age Ageing. 2016;45:345-52.

45. Robertson MC, Gardner MM, Devlin N, McGee R, Campbell AJ. Effectiveness and economic evaluation of a nurse delivered home exercise programme to prevent falls. 2: controlled trial in multiple centres. BMJ. 2001;322:701-4.

46. Skelton D, Dinan S, Campbell M, Rutherford O. Tailored group exercise (falls management exercise - FaME) reduces falls in community-dwelling older frequent fallers (an RCT). Age Ageing. 2005;34:636-9.

\section{Publisher's Note}

Springer Nature remains neutral with regard to jurisdictional claims in published maps and institutional affiliations.

Ready to submit your research? Choose BMC and benefit from:

- fast, convenient online submission

- thorough peer review by experienced researchers in your field

- rapid publication on acceptance

- support for research data, including large and complex data types

- gold Open Access which fosters wider collaboration and increased citations

- maximum visibility for your research: over $100 \mathrm{M}$ website views per year

At BMC, research is always in progress.

Learn more biomedcentral.com/submissions 